\title{
NIDCAP Influences Maternal/Newborn Health in the Embrace Refugee Birth Support Program
}

Frankel K.

Private Practice, Developmental Specialist, Atlanta, GA USA

Member of Emory University Perinatal Behavioral Support Project

Friends of Refugees: Embrace Birth Family Mentor

DOI: 10.14434/do.v13i1.29077

\section{Aims/Purpose}

Approximately 95,000 people are living in refugee camps on the border of Thailand and Burma (Myanmar). ${ }^{1,2}$ Ethnic minorities (Chin, Karen and others) who have fled conflict for over 30 years have registered with the United Nations to be resettled in a third country. Many escaped as children and grew up with limited education, healthcare, and job opportunities. A large group has resettled in Georgia finding employment in chicken processing facilities an hour north of the city. Fathers leave their families 12 hours per day. Pregnant women in this community are at risk for poor prenatal care due to lack of transport, caring for other children, and lapses in Medicaid coverage. ${ }^{4,5}$ New arrivals struggle to learn English and to adapt to American customs. The strengths of the community are apparent in their humble nature, diet of proteins, homegrown vegetables and rice, value of the nuclear family, and nurturing of their children in close contact. This population is vulnerable when encountering the healthcare system due to language, cultural differences and lack of understanding of American healthcare practices. ${ }^{4,5}$

The Embrace program is a community effort which identifies pregnant immigrant women and pairs them with caring mentors. The mentor accompanies the woman through childbirth and all prenatal, postpartum, and early pediatric appointments. The aim here is to describe how an adaptation of NIDCAP principles can provide a culturally sensitive framework for individualized assessment and care while mentoring a Karen mother. The goal was to minimize the effects of stress of birth and hospital encounters, and improve maternal/infant birth experiences by employing principles of family centered individualized care, observation, and reflection. ${ }^{6}$

\section{Methods}

A 28 year-old Gravida 5 Para 4 Burmese mother had two normal deliveries in a refugee camp prior to arrival in the US in 2013. Her third pregnancy ended in fetal demise. During her 5th pregnancy she missed prenatal appointments and was labeled as high risk. English was limited and she had an extremely humble nature in the face of challenges. The Embrace mentor, a NIDCAP trained provider, established trust and friendship by accompanying her to birth classes (instructed by another Karen immigrant) where she was educated on delivery, hospital policies, infant care, and family planning. She developed a pictorial narrative of her birth plan. The mentor transported her to prenatal appointments where there was the opportunity to observe and interpret her responses to medical information, seeing the ultrasound of her baby, and painful procedures.

\section{Findings}

Labor occurred spontaneously at 39 weeks. Careful observation revealed that contractions were coming 10 minutes apart. She was transported to the hospital and assessed as $4 \mathrm{~cm}$ dilated. The mentor remained at the mother's side and counted contractions. Labor progressed rapidly with low intensity responses from the mother. The baby was moderately distressed at birth requiring suction and stimulation. The NIDCAP trained mentor supported the infant on the warming table and in transition to the mother's chest. The infant improved his status and was monitored with pulse oximetry. The mentor offered to observe the infant carefully so that mother and baby could have protected skin to skin time. In the 48 hours after the birth, NIDCAP principles of modifying the environment, observation, positioning, supporting with painful procedures, and maximizing skin to skin were instituted. ${ }^{6,7}$

\section{Conclusion}

Family integrated, relationship based, culturally sensitive, and responsive maternal-infant interactions were the NIDCAP principles implemented improving the experience for this mother and infant. As stated in the NIDCAP vision statement, care was individualized, enhancing strengths and minimized the stress of hospitalization of a newborn and his family. An evidence-based approach of observation, evaluation, modification and reflection was employed. ${ }^{6,7}$ It is the hope of this author that NIDCAP training could be used in diverse settings and with people in need of sensitive caregiving.

References

1. https://worldreliefffortworth.org Burma(Myanmar) Karen cultural profile/2018

2. https://ethnomed.org/culture/karen/karen-cultural-profile

3. https:www.statelgov/refugee-admissions Department of State Bureau of population refugees and migration

4. Dyer JM, Baksh L. A study of pregnancy and birth outcomes among African-born Women living in Utah. National Center on Immigrant integration policy, Nov 2016.

5. Grace LB, Bais R, Roth BJ. The Violence of Uncertainty Undermining Immigrant and Refugee Health. New England Journal of Medicine 9/6/2018.

6. Als $\mathrm{H}$. A synactive model of neonatal behavioral organization: Framework for the assessment and support of the neurobehavioral development of the premature infant and his parents in the environment of the neonatal intensive care unit. In Sweeney JK (ed.), The High-Risk Neonate: Developmental Therapy Perspectives. Physical and Occupational Therapy in Pediatrics 1986, 6(3/4):3-55.

7. https://nidcap.org/wp-content/uploads/2018/missionandvision 